\title{
Search of New Scaffolds against N-myristoyltransferase for Antifungal Activity
}

\author{
Sudha Vengurlekar ${ }^{1^{*}}$ and Reena Gupta ${ }^{2}$ \\ ${ }^{1}$ Sri Aurobindo Institute of Pharmacy, Indore, India \\ ${ }^{2}$ Smriti College of Pharmaceutical Education, Indore, India \\ Email: sudha_ven@rediffmail.com
}

\begin{abstract}
N$-myristoyltransferase (NMT) has been an emerging target for the design of novel antifungal agents with new mode of action. A series of furan and imidazole containing heterocyclic derivatives have been designed using rational drug designing approach as NMT inhibitors. Newly Designed compounds were synthesized, characterized and evaluated for their antifungal activity against NMT. Synthesized compounds were characterized by IR, NMR and Mass. In vitro antifungal assay indicated that these derivatives have shown moderate to good antifungal activity against five fungal strains. A possible antifungal target was identified (NMT) and furan derivatives showed more favorable affinity than the imidazole ligands.
\end{abstract}

Keywords: N- myristoyltranseferase, antifungal, antibacterial, molecular modeling, minimum inhibitory concentration.

\section{Introduction}

Invasive fungal infections have increased dramatically in recent years to become important causes of morbidity and mortality in hospitalized patients [1-3]. $N$-myristoyltransferase (NMT) has been a promising new target for the design of novel antifungal agents with new mode of action. NMT catalyzes the covalent co-translational attachment of the fatty acid, although some myristoylated proteins are cytosolic, many are associated with cellular membranes where myristoylation facilitates membrane attachment. The addition of myristate can also stabilize protein-protein interactions, and many acylated proteins require this modification for full expression of their biological function. Genetic studies have shown that the NMT gene is essential for the survival of Saccharomyces cerevisiae and the pathogenic fungi, Candida albicans and Cryptococcus neoformans [4]. The enzyme NMT is essential for viability of C. albicans, which is a major cause of systemic fungal infection in immunocompromised patients [5, 6]. Therefore it is worthwhile to develop new inhibitors against NMT. Imidazoles are important class of compounds that have shown multiple therapeutic actions and have been widely used including as antifungals $[7,8]$. There is a report that compounds containing furan nucleus exhibited inhibitory effect on NMT of $C$. albicans $\lceil 9,10\rceil$ and antimicrobial $\lceil 11,12\rceil$ activities. In view of the potential pharmacophoric nature of imidazole and furan nucleus and affinity of furan nucleus with NMT [13], compounds containing both imidazole and furan nucleus were designed rationally with the aim to have synergistic effect on target, synthesized and evaluated for their antifungal activity. Docking studies were performed to get more insight on binding affinities of synthesized analogues to the target NMT.

\section{$2 \quad$ Materials and Methods}

All reagents were purchased from Sigma-Aldrich and were used without further purification. All melting points of synthesized compounds were determined by open capillary method and are uncorrected. IR spectra were recorded with Shimadzu FT-IR-8400S spectrophotometer on KBr. Elemental analysis $(\% \mathrm{C}, \% \mathrm{H}, \% \mathrm{~N}, \% \mathrm{O}$ and $\% \mathrm{~S})$ of the synthesized compounds was done on Corlo Erba 1108 Heracus instrument at Central Drug Research Institute (CDRI), Lucknow, India. The ${ }^{1} \mathrm{H}$ NMR spectra were 
recorded on an Advance - $400 \mathrm{MHz}$ Bruker, using TMS as an internal reference and mass spectra were obtained on a JMS-T100LC, Accu TOF (DARTMS) spectrophotometer at CDRI, Lucknow, India.

\subsection{Synthesis of Compound 1a, 1b}

A solution of Salicylaldehyde $(1 \mathrm{mmol})$ and substituted ketones $(1 \mathrm{mmol})$ in $5-7 \mathrm{~mL}$ of ethanol was allowed to react with $3 \mathrm{~mL}$ of $60 \% \mathrm{KOH}$ solution at $5-10{ }^{\circ} \mathrm{C}$ with stirring for $4 \mathrm{hrs}$. Reaction mixture was then diluted with water $(10 \mathrm{~mL})$ and extracted with diethyl ether. The aqueous solution was acidified with dilute $\mathrm{HCl}$. The solid obtained was filtered, washed thoroughly with water and dried. The crude product was purified by crystallization from benzene: $\mathrm{MeOH}(3: 2)$ and resulted in 1a and 1b [13].

3-(2-hydroxyphenyl)-1-(1H-imidazol-1-yl)prop-2-en-1-one (1a) was obtained as cream colored crystals, mp 145-148 ${ }^{\circ} \mathrm{C}$; ir: $\mathrm{C}=\mathrm{O}$ 1706.1, C-O 1210, C-N 1221.8, $\mathrm{C}=\mathrm{C} 1610, \mathrm{C}=\mathrm{N}$ 1312.6, $\mathrm{OH} 3295.8 ;{ }^{1} \mathrm{H}$ NMR: 6.50 (s, 2H, ethylene), 5.01 (s, Ar-OH), 6.60-7.10 (Ar-H), 7.10-7.73 (Imidazole-CH); Mass m/z: 214 $\left\lceil\mathrm{M}+1\right.$; Anal. Calcd. for $\mathrm{C}_{12} \mathrm{H}_{14} \mathrm{~N}_{2} \mathrm{O}_{2}$ : C, 66.65; H, 5.59; N, 12.96; O, 14.80. Found: C, 65.60; H, 5.10; N, 12.08; O, 13.90, yield-71\%.

1-(furan-2-yl)-3-(2-hydroxyphenyl)prop-2-en-1-one 1(b) was obtained as white crystals, mp: 182-185 ${ }^{\circ} \mathrm{C}$; ir: $\mathrm{C}=\mathrm{O}$ 1679.3, C-O 1022.1, OH 3261.3, $\mathrm{C}=\mathrm{C}$ Ar 1561.2, $\mathrm{C}=\mathrm{N}$ 1251.1; ${ }^{1} H$ NMR: 6.50-7.81 (s, 2H,ethylene), 5.04 (s, Ar-OH), 6.60-7.10 (Ar-H), 6.62-7.73 (CH, furon); Mass m/z: $214[\mathrm{M}+]$; Anal. Calcd. for $\mathrm{C}_{13} \mathrm{H}_{10} \mathrm{O}_{3}$ : C, 72.89; H, 4.71; O, 22.41. Found: C, 72.29; H, 4.23; O, 22.11; yield- $80 \%$.

\subsection{Synthesis of Compounds 2a, 2b}

The compounds $1(\mathrm{a}, \mathrm{b})(1 \mathrm{mmol})$ and thiourea $(1 \mathrm{mmol})$ in $5 \mathrm{~mL}$ ethanol was added with $0.5 \mathrm{~mL}$ of $\mathrm{KOH}$ solution $(0.02 \mathrm{~mol})$. The reaction mixture was refluxed for $4-5 \mathrm{hrs}$. The reaction mixture was then poured in $10 \mathrm{~mL}$ of $10 \% \mathrm{HCl}$ solution (cold) and the precipitate was filtered, washed with water until free from acid and recrystallized from benzene-ethanol, which gave compound $2 \mathrm{a} \& 2 \mathrm{~b}$ [13].

2-(2-amino-4-(1H-imidazol-1-yl)-6H-1,3-thiazin-6-yl)phenol (2a) was obtained as white needle like

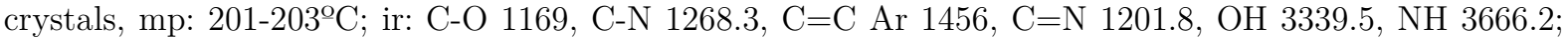
${ }^{1} H$ NMR (DMSO-d6, $\left.300 \mathrm{MHz}, \mathrm{ppm}\right): 2.07\left(\mathrm{~s}, \mathrm{NH}_{2}\right), 4.58(\mathrm{~s}, \mathrm{CH}), 5.06$ (s, Ar-OH), 6.35- (s, CH, ethylene), 6.67-7.18 (Ar-H), 7.10-7.70 (CH, Imidazole); Mass m/z: $273\lceil\mathrm{M}+1 ;$ Anal. Calcd. for $\mathrm{C}_{12} \mathrm{H}_{11} \mathrm{~N}_{1} \mathrm{OS}$ : C. 56.91; H, 5.14; N, 20.42; O, 5.83; S, 11.69. Found: C, 56.41; H, 5.02; N, 20.82; O, 5.42; S, 11.10; Yield-76\%.

2-(2-amino-4-(furan-2-yl)-6H-1,3-thiazin-6-yl)phenol (2b) was obtained as yellow crystalline compound, mp: $213-216{ }^{\circ} \mathrm{C}$; ir: $\mathrm{C}-\mathrm{O} 1169, \mathrm{C}-\mathrm{N}$ 1268.3, $\mathrm{C}=\mathrm{C}$ Ar 1456, $\mathrm{C}=\mathrm{N}$ 1201.8; O-H,3339.5, NH 3666.2; ${ }^{1} H$ NMR (DMSO-d6, $300 \mathrm{MHz}, \mathrm{ppm}): 2.04\left(\mathrm{~s}, \mathrm{NH}_{2}\right.$ ), 4.50 (s, CH), 5.21 (s, Ar-OH), 6.70 (s, CH, ethylene), 6.70-6.90 (Ar-H), 6.31-7.40 ( $\mathrm{CH}$, Imidazole); Mass m/z: $273\left\lceil\mathrm{M}+1\right.$; Anal. Calcd. for $\mathrm{C}_{11} \mathrm{H}_{1}, \mathrm{~N}_{2} \mathrm{O}_{2} \mathrm{~S}: \mathrm{C}$, 61.75 ; H, 4.44; N, 10.29; O, 11.75; S, 11.77. Found: C, 61.20; H, 4.34; N, 10.54; O, 11.30; S, 10.98; yield$68 \%$.

\subsection{Synthesis of Compounds 3a, 3b}

A solution of $1 \mathrm{a}$ and $1 \mathrm{~b}(0.001 \mathrm{~mol})$ and guanidine hydrochloride $(0.001 \mathrm{mmol})$ in $5 \mathrm{~mL}$ ethanol was added with $0.5 \mathrm{~mL}$ of aqueous $\mathrm{NaOH}(0.02 \mathrm{~mol})$. The reaction mixture was refluxed for $6 \mathrm{hrs}$. The reaction mixture was poured in $5 \mathrm{~mL}$ of $10 \% \mathrm{HCl}$ solution (cold) and the precipitate was filtered, washed with water until free from acid and recrystallized from benzene: ethanol, which gave compound $3 \mathrm{a}$ and $3 \mathrm{~b}[13]$.

2-(2-amino-6-(1H-imidazol-1-yl)pyrimidin-4-yl)phenol (3a) was obtained as white powder, mp: 150$153{ }^{\circ} \mathrm{C}$; ir: C-O 1032.3, C-N 1231.5, C=C Ar 1455.9, C=N 1231.5, C-H 2949.8, O-H 3240, NH 3364.8; ${ }^{1} H$ NMR (DMSO-d6, $300 \mathrm{MHz}, \mathrm{ppm}): 4.01$ (s, Ar-CNH), 5.00 (s, Ar-OH), 6.72 (s, CH), 6.80-7.50 (Ar-H), 7.41-8.40 (CH, Imidazole); Mass m/z: 253 [M+]; Anal. Calcd. for $\mathrm{C}_{13} \mathrm{H}_{15} \mathrm{~N}_{5} \mathrm{O}: \mathrm{C}, 60.69 ; \mathrm{H}, 5.88 ; \mathrm{N}, 27.22$. Found: C, 60.68; H, 5.11; N, 27.34; yield-83\%.

2-(2-Amino-6-furan-2-yl-pyrimidin-4-yl)-phenol (3b) was collected as white crystalline solid, mp: 170$171{ }^{\circ} \mathrm{C}$; ir: $\mathrm{C}-\mathrm{O} 1032.3, \mathrm{C}-\mathrm{N} 1231.5, \mathrm{C}=\mathrm{C}$ Ar 1455.9, C=N 1231.5, C-H 2949.8, O-H 3239.5, N-H 3364.8; ${ }^{1} H$ NMR (DMSO-d6, $\left.300 \mathrm{MHz}, \mathrm{ppm}\right): 4.04$ (s, Ar-CNH); 5.08 (s, Ar-OH); 6.90 (s, CH); 6.80-7.51 (Ar-H). 
6.30-7.44 (CH, Furon); Mass m/z: 253 「M+l. Anal. Calcd. for $\mathrm{C}_{13} \mathrm{H}_{14} \mathrm{~N}_{3} \mathrm{O} 2: \mathrm{C}, 65.87 ; \mathrm{H}, 5.13 ; \mathrm{N}, 16.46 ; \mathrm{O}$, 12.54. Found: C, 65.07; H, 5.33; N, 16.24; O, 12.12; yield-79\%.

\subsection{Synthesis of Compound 4}

Salicyaldehyde $(2 \mathrm{mmol})$ and trioxane $(3 \mathrm{mmol})$ in $6 \mathrm{~mL}$ of glacial acetic acid was heated to a temperature of $90-95{ }^{\circ} \mathrm{C}$ under nitrogen atmosphere. $1 \mathrm{~mL}$ of mixture of concentrated sulfuric acid and glacial acetic acid (1:45) was added drop wise. The temperature was maintained for $22 \mathrm{hr}$ while stirring was continued during the entire period. Subsequently, the reaction mixture was poured into $200 \mathrm{~mL}$ of ice-water and allowed to stand overnight. The precipitated solid was filtered and extracted twice with nhexane. Recrystallization from acetone resulted to compound 4 [14].

\subsection{Synthesis of Compound $5 \mathrm{a}, 5 \mathrm{~b}$}

A solution of $4(1 \mathrm{mmol})$ and substituted compound $(3 \mathrm{mmol})$ in 5-7 $\mathrm{mL}$ of ethanol was treated with 3 $\mathrm{mL}$ of $60 \% \mathrm{KOH}$ solution at $5-10^{\circ} \mathrm{C}$. The reaction mixture was stirred at room temperature for $4 \mathrm{hrs}$. Reaction mixture was diluted with water $(10 \mathrm{~mL})$ and extracted with diethyl ether. The aqueous solution was acidified with dil HCl. The solid obtained was filtered, washed thoroughly with water and dried. The crude product was purified by crystallization from benzene: $\mathrm{MeOH}(3: 2)$ to obtain compound $5 \mathrm{a}$ and $5 \mathrm{~b}[14,15]$.

(2E,2'E)-3,3'-(5,5'-methylenebis(2-hydroxy-5,1-phenylene))bis(1-(1H-imidazol-1-yl)prop-2-en-1-one) (5a) was obtained as creamish white crystalline compound, mp: $159-161{ }^{\circ} \mathrm{C}$; ir: C-O 1094.8, C-N 1231.5, $\mathrm{C}=\mathrm{C}$ Ar 1634.6 and 1448.8, $\mathrm{C}=\mathrm{N}$ 1363.9, $\mathrm{C}=\mathrm{O}$ 1711.5, O-H 3333.1; ${ }^{1} \mathrm{H}$ NMR (DMSO-d6, $300 \mathrm{MHz}$, ppm): $3.81\left(\mathrm{CH}_{2}\right), 5.03$ (s, 2Ar-OH), 6.50-7.81 (s, $\left.\mathrm{CH}\right), 6.51-6.70$ (Ar-H). 7.31-7.62 (CH, imidazole); Mass m/z: $440\lceil\mathrm{M}+\rceil$; Anal. Calcd. for $\mathrm{C}_{25} \mathrm{H}_{24} \mathrm{~N}_{4} \mathrm{O}_{4}$ : C, 67.55; H, 5.44; N,12.60; O, 14.40. Found: C, 67.87; H, 5.20; N, 12.37; O, 14.21; yield-78\%.

1-Furan-2-yl-3-\{5-[3-(3-furan-2-yl-3-oxo-propenyl)-4-hydroxy-benzyl]-2-hydroxy-phenyl $\}$-propenone (5b) was obtained as brown crystals, mp: 230-232 ${ }^{\circ} \mathrm{C}$; ir: 1094.8; C-O, 1231.5; C-N, 1634.6 and 1448.8; $\mathrm{C}=\mathrm{C}$ Ar, 1363.9; $\mathrm{C}=\mathrm{N}, 1711.5 ; \mathrm{C}=\mathrm{O}, 3333.1 ; \mathrm{OH} ;{ }^{1} \mathrm{H}$ NMR (DMSO-d6, $\left.300 \mathrm{MHz}, \mathrm{ppm}\right): 3.82\left(\mathrm{CH}_{\text {}}\right)$, 5.01 (s, 2Ar-OH), 6.52-7.83 (s, CH), 6.50-6.91 (Ar-H), 6.60-7.71 (CH, furon), Mass m/z: $440\lceil\mathrm{M}+] ;$ Anal. Calcd. for $\mathrm{C}_{27} \mathrm{H}_{20} \mathrm{O}_{6}$ : C, 73.63; H, 4.58; O, 21.80. Found: C, 73.21; H, 4.43; O, 21.57; yield-76\%.

\subsection{Synthesis of Compounds $6 \mathrm{a}, 6 \mathrm{~b}$}

A solution of $5 \mathrm{a}, 5 \mathrm{~b}(0.01 \mathrm{~mol})$ and thiourea $(0.03 \mathrm{~mol})$ in $10 \mathrm{~mL}$ ethanol was added with $5 \mathrm{~mL}$ alcoholic $\mathrm{KOH}(0.02 \mathrm{~mol})$ and refluxed for $5 \mathrm{hrs}$. The reaction mixture was poured in $10 \mathrm{~mL}$ of $10 \% \mathrm{HCl}$ solution (cold) and the precipitate was filtered, washed with water until free from acid and recrystallized from benzene-ethanol to obtain compound $6 \mathrm{a}$ and $6 \mathrm{~b}[14]$.

4,4'-methylenebis(2-(2-amino-4-(1H-imidazol-1-yl)-6H-1,3-thiazin-6-yl)phenol (6a) was obtained as white crystals, mp: $172-173{ }^{\circ} \mathrm{C}$; ir: $\mathrm{C}-\mathrm{O}$ 1091.2, C-N 1224.3, C=C Ar 1601.9, C=N 1191.3, O-H 3272.6, N-H 3303.7; ${ }^{1} \mathrm{H}$ NMR (DMSO-d6, $\left.300 \mathrm{MHz}, \mathrm{ppm}\right): 2.03\left(\mathrm{NH}_{2}\right), 3.81\left(\mathrm{CH}_{2}\right), 4.51(\mathrm{CH}), 5.00$ (s, 2Ar-OH), $6.30(\mathrm{CH}), 6.53-7.81(\mathrm{~s}, \mathrm{CH}), 6.40-6.72(\mathrm{Ar}-\mathrm{H}), 7.11-7.70(\mathrm{CH}$, Imidazole); Mass m/z: 557 [M+1; Anal. Calcd. for $\mathrm{C}_{77} \mathrm{H}_{98} \mathrm{~N}_{8} \mathrm{O}_{2} \mathrm{~S}_{2}$ : C, 57.84; H, 5.03; N, 19.98; O, 5.71; S, 11.44. Found: C, 57.13; H, 5.44; N, 19.32; $\mathrm{O}, 5.22 ; \mathrm{S}, 11.21$; yield- $73 \%$.

4,4'-methylenebis(2-(2-amino-4-(1H-furan-1-yl)-6H-1,3-thiazin-6-yl)phenol (6b) was obtained as yellow crystals, mp: 179-181; ir: 1091.2; C-O, 1224.3; C-N; 1601.9; C=C Ar, 1191.3; C=N, 3272.6; OH, 3303.7; $\mathrm{NH} ;{ }^{1} \mathrm{H}$ NMR (DMSO-d6, $\left.300 \mathrm{MHz}, \mathrm{ppm}\right): 2.00\left(\mathrm{NH}_{2}\right), 3.80\left(\mathrm{CH}_{2}\right), 4.50(\mathrm{CH}), 5.01$ (s, 2Ar-OH), 6.30 (CH), 6.50-7.81 (s, CH), 6.41-6.72 (Ar-H), 6.30-7.62 (CH, furan); Mass m/z: $556\lceil\mathrm{M}+\rceil$; Anal. Calcd. for $\mathrm{C}_{90} \mathrm{H}_{21} \mathrm{~N}_{1} \mathrm{O}_{1} \mathrm{~S}_{2}$ : C, 62.57; H, 4.35; N, 10.06; O, 11.50; S, 11.52. Found: C, 63.07; H, 4.76; N, 10.23; O, 11.12; S, 11.14; yield-69\%.

\section{$3 \quad$ In Vitro Antifungal Activity}

Evaluations of the susceptibility of fungal strains were performed using macro tube dilution method as per NCCLS guidelines [16]. The fungi used as inocula were grown overnight on sabouraud dextrose agar 
(SDA) at $25 \pm 1^{\circ} \mathrm{C}$. To $5 \mathrm{ml}$ of SDA, $0.2 \mathrm{ml}$ of culture was added and inoculated followed by incubation till it reached the turbidity equal to that of the standard $0.5 \mathrm{McFarland}$ solution in $0.9 \%(\mathrm{w} / \mathrm{v}) \mathrm{NaCl}$ at $600 \mathrm{~nm}$ which was equivalent to $10^{6}-10^{8} \mathrm{CFU} / \mathrm{ml}$. A stock solution of $10 \mathrm{mg} / \mathrm{mL}$ was prepared in dimethyl sulfoxide (DMSO, Sigma) for the various synthesized compounds and for fluconazole (FLC), which was used as control. Two fold dilutions of test compounds from 256 to $0.25 \mu \mathrm{g} / \mathrm{mL}$ were prepared with the suspension of the inoculum. The micro dilution tubes, which contained $0.1 \mathrm{~mL}$ of the serially diluted drug, were inoculated with $0.1 \mathrm{~mL}$ of the resulting suspension. The final inoculum concentration after dilution with the drug suspension was $10^{3} / 10^{4}$ cells per mL. Two tubes containing the drug-free medium and inoculum were used as controls. The inoculated tubes were incubated at $35 \pm 1{ }^{\circ} \mathrm{C}$ for $48 \mathrm{~h}$ (Candida sp.) and $72 \mathrm{~h} \mathrm{(A.} \mathrm{niger)} \mathrm{in} \mathrm{ambient} \mathrm{air.} \mathrm{The} \mathrm{growth} \mathrm{in} \mathrm{each} \mathrm{tube} \mathrm{was} \mathrm{then} \mathrm{visually} \mathrm{estimated.}$ The minimum inhibitory concentrations (MIC) were determined visually, and were defined as the lowest concentration of a compound that inhibits growth of the organism as detected visually.

\section{Antibacterial Activity}

Evaluations of the susceptibility of bacterial strains were made by the macro tube dilution method as per NCCLS guidelines [16]. Mueller-Hinton broth was used as the test medium. An inoculum of approximately $5 \times 10^{5} \mathrm{CFU} \mathrm{\textrm {cm } ^ { - 3 }}$ was used. Serial twofold dilutions of the test compounds (256-0.25 $\mu \mathrm{g} / \mathrm{mL})$ and extra dilutions $(0.12-0.015 \mu \mathrm{g} / \mathrm{mL})$ for antibiotic standard (ciprofloxacin) was prepared. Tubes were incubated for $24 \mathrm{hrs}$ at $37 \pm 1^{\circ} \mathrm{C}$ in an ambient air incubator. The lowest concentration of the test compounds inhibiting visible growth was taken as the MIC value.

\section{$5 \quad$ Docking Studies}

\subsection{Software}

Surflex 2.0 tools of Sybyl software were utilized to generate protomol, calculate dock score and evaluate conformers. The scoring function used by surflex is derived from the Hammerhead's empirical scoring function with a molecular similarity method (morphological similarity) to generate putative poses of ligand fragments. The active binding site region was defined as a spherical region which encompasses all protein of bound crystallographic ligand atom. Surflex is available free of charge to academic researchers for noncommercial use (see http://jainlab.ucsf.edu for details on obtaining the software).

\subsection{Ligand Preparation}

The structures of ten compounds (1a-6b) were converted into suitable chemical information using Chemdraw ultra 7.0 (Cambridge software), copied to Chem3D ultra 7.0 to create a 3D model using sybyl surflex-x 2.0 integral option.

\subsection{Docking Method}

The crystal structure of target NMT was retrieved from the RCSB Protein Data Bank (PDB entry code: 4A33). The ligands were docked into corresponding protein's binding site by an empirical scoring function and a patented search engine in Surflex-Dock. All ligands and water molecules in target have been deleted and the polar hydrogen atoms were added to target. Protomol, a representation of a ligand making every potential interaction with the binding site, was applied to guide molecular docking. Then, the MOLCAD (Molecular Computer Aided Design) program was employed to visualize the binding mode between the protein and ligand. MOLCAD calculated and exhibited the surfaces of channels and cavities, as well as the separating surface between protein subunits. Moreover, Surflex-Dock total scores, which were expressed in $-\log 10(\mathrm{Kd})$ units to represent binding affinities, were applied to estimate the ligand-receptor interactions of newly designed molecules. The best poses of the studied compounds within the active sites of target enzymes are displayed in figure 2. 


\section{$6 \quad$ Results}

Structural features responsible for antifungal activity have been collected such as imidazole, furan, thiazine, hydroxyl group at aromatic ring etc., and were used to design new molecules with the hope to have synergistic effect against fungal strains. Salicylaldehyde and thiourea and some substituted ketones were utilized as synthetic blocks for the synthesis of ten compounds as depicted in Scheme 1 and Scheme 2.

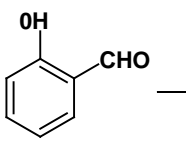

Salicylaldehyde

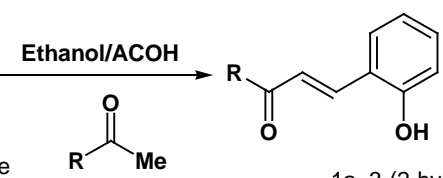

1a. 3-(2-hydroxyphenyl)-1-(1H-imidazol-1-yl)prop-2-en-1-one 1b. 1-(furan-2-yl)-3-(2-hydroxyphenyl)prop-2-en-1-one

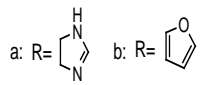

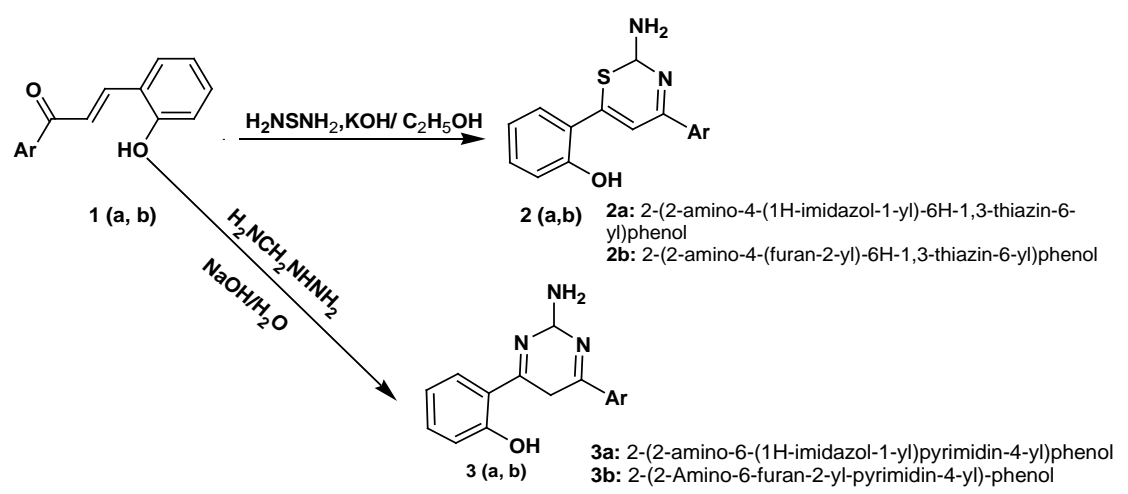

Scheme 1. Synthetic pathway for the target molecules.

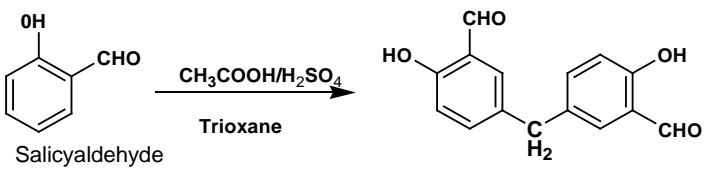<smiles>O=Cc1cc(Cc2ccc(O)c(C(=O)O)c2)ccc1O</smiles>

4

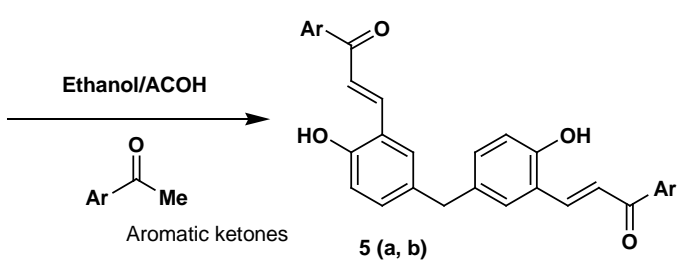

5a: (2E, 2'E)-3,3'-(5,5'-methylenebis(2-hydroxy-5,1phenylene))bis(1-(1H-imidazol-1-yl)prop-2-en-1-one) 5b: 1-Furan-2-yl-3-\{5-[3-(3-furan-2-yl-3-oxo-propenyl)-4hydroxy-benzyl]-2-hydroxy-phenyl\}-propenone

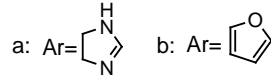




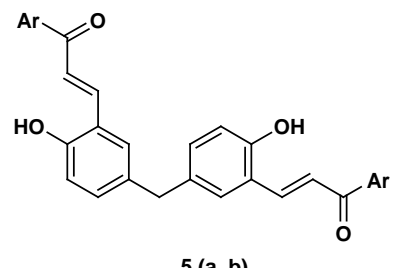

$5(a, b)$

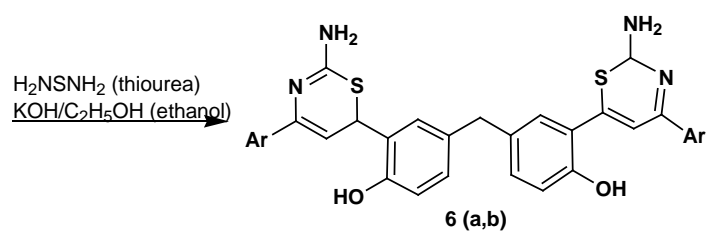

6a: 4,4'-methylenebis(2-(2-amino-4-(1H-imidazol1-yl)-6H-1,3-thiazin-6-yl)phenol 6b: 4,4'-methylenebis(2-(2-amino-4-(1H-furan-1 yl)-6H-1,3-thiazin-6-yl)phenol

a: $\operatorname{Ar}=\left[\begin{array}{l}\mathrm{H} \\ N\end{array}\right.$ b: $\operatorname{Ar}=\llbracket$

Scheme 2. Synthetic pathway for the target molecules.

All synthesized compounds were evaluated for antifungal and antibacterial activity using macro tube dilution method. The results were indicated in Table 1 and Table 2. Docking studies were performed on synthesized compound to evaluate the binding affinity of all 10 compounds to the target and docking scores are shown in Table 3, binding affinities are shown in Figure 1 and 2.

Table 1. MIC values of synthesized compounds against fungal strains.

\begin{tabular}{|c|c|c|c|c|c|c|}
\hline \multirow[t]{2}{*}{ Sr. No. } & \multirow[t]{2}{*}{ Compound code } & \multicolumn{5}{|c|}{ MIC value in $\mu \mathrm{g} / \mathrm{mL}$} \\
\hline & & A & B & $\mathrm{C}$ & $\mathrm{D}$ & $\mathbf{E}$ \\
\hline 1. & $1 \mathrm{a}$ & 16 & 64 & 64 & 64 & 32 \\
\hline 2. & $1 b$ & 8 & 8 & 16 & 16 & 16 \\
\hline 3. & $2 \mathrm{a}$ & 32 & 8 & 8 & 8 & 32 \\
\hline 4. & $2 \mathrm{~b}$ & 8 & 8 & 16 & 8 & 8 \\
\hline 5. & $3 a$ & 16 & 32 & 32 & 32 & 32 \\
\hline 6. & $3 b$ & 8 & 8 & 8 & 8 & 16 \\
\hline 7. & $5 \mathrm{a}$ & 16 & 16 & 8 & 8 & 32 \\
\hline 8. & $5 b$ & 2 & 2 & 2 & 2 & 16 \\
\hline 9. & $6 a$ & 16 & 16 & 8 & 8 & 64 \\
\hline 10 . & $6 \mathrm{~b}$ & 2 & 2 & 2 & 2 & 32 \\
\hline 11. & Fluconazole & 1 & 2 & 2 & 1 & 2 \\
\hline
\end{tabular}

$* \mathrm{~A}=$ A. niger ATCC 9029, $\mathrm{B}=$ C. albicans ATCC 24433, $\mathrm{C}=$ C. albicans ATCC $10231, \mathrm{D}=$ C. tropicalis ATCC 13803, $\mathrm{E}=$ P. chrysogenum ATCC 10002

Table 2. MIC values of synthesized compounds against bacterial strains.

\begin{tabular}{|c|c|c|c|c|c|c|}
\hline \multirow[t]{2}{*}{ Sr. No. } & \multirow[t]{2}{*}{ Compound } & \multicolumn{5}{|c|}{${ }^{*}$ Tested bacterial strains (MIC $\left.\mu \mathrm{g} / \mathrm{mL}\right)$} \\
\hline & & A & B & $\mathrm{C}$ & $\mathrm{D}$ & $\mathbf{E}$ \\
\hline 1. & $1 \mathrm{a}$ & 64 & 64 & 64 & 64 & 32 \\
\hline 2. & $1 b$ & 64 & 64 & 64 & 64 & 64 \\
\hline 3. & $2 \mathrm{a}$ & 64 & 64 & 64 & 64 & 64 \\
\hline 4. & $2 \mathrm{~b}$ & 64 & 64 & 64 & 64 & 64 \\
\hline 5. & $3 \mathrm{a}$ & 64 & 32 & 32 & 32 & 64 \\
\hline 6. & $3 \mathrm{~b}$ & 64 & 64 & 64 & 64 & 64 \\
\hline 7. & $5 \mathrm{a}$ & 64 & $>64$ & $>64$ & 64 & 64 \\
\hline 8. & $5 b$ & 64 & 32 & 16 & 64 & 64 \\
\hline 9. & $6 \mathrm{a}$ & 64 & 64 & 64 & 64 & 64 \\
\hline 10. & $6 \mathrm{~b}$ & 64 & 64 & 64 & 64 & 64 \\
\hline 11. & Ciprofloxacin & 8 & 2 & 2 & 8 & 16 \\
\hline
\end{tabular}

$* \mathrm{~A}=$ Pseudomonas aeruginosa ATCC 9027, $\mathrm{B}=$ Staphylococcus aureus ATCC, $\mathrm{C}=$ Staphylococcus aureus ATCC 25923, D= Serratia marcescens ATCC 13880, E= Escherichia coli ATCC 8739 
Table 3. Docking scores of synthesized compounds

\begin{tabular}{cccc}
\hline Compound no. & Total Score & Cresh Score & Polar bond \\
\hline 6b & 6.6574 & -1.9554 & 1.1974 \\
$5 \mathrm{~b}$ & 5.8645 & -1.3212 & 1.3283 \\
$5 \mathrm{a}$ & 5.6161 & -1.5472 & 2.3208 \\
$2 \mathrm{a}$ & 4.8948 & -0.9298 & 1.0850 \\
$3 \mathrm{a}$ & 3.5286 & -0.4377 & 1.7720 \\
$6 \mathrm{a}$ & 3.3946 & -1.7743 & 1.2591 \\
$1 \mathrm{a}$ & 3.0508 & -0.6627 & 1.1781 \\
$1 \mathrm{~b}$ & 2.9090 & -0.3017 & 0.8928 \\
3b & 2.7736 & -0.6045 & 1.3420 \\
$\mathrm{2b}$ & 2.5438 & -0.4673 & 1.6022 \\
\hline
\end{tabular}

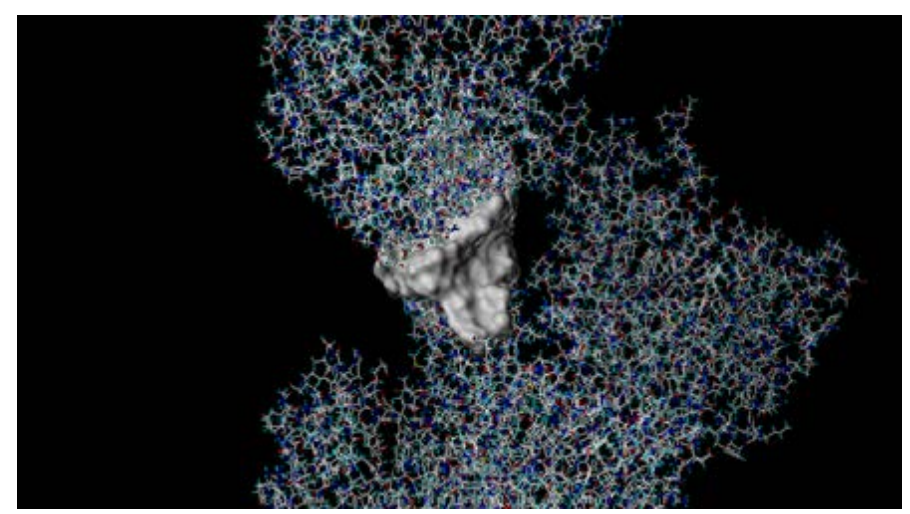

Figure 1. Active binding site region of selected antifungal drug target $\mathrm{N}$-myristoyltransferase (PDB entry code: $4 \mathrm{~A} 33)$

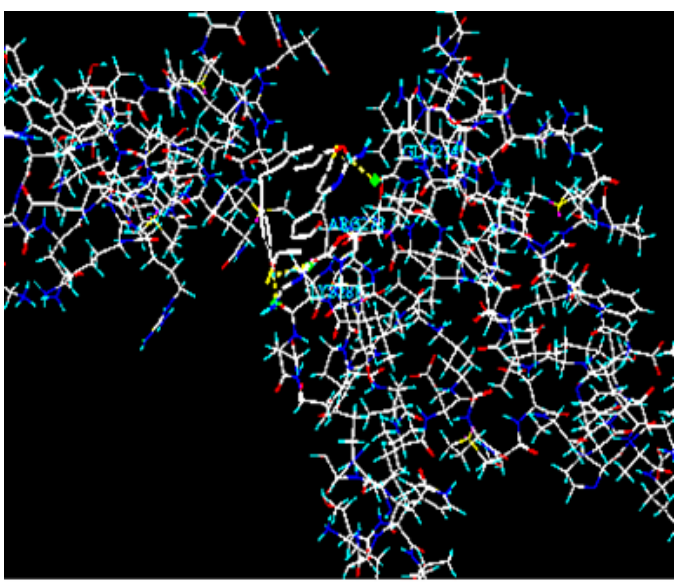

(A)

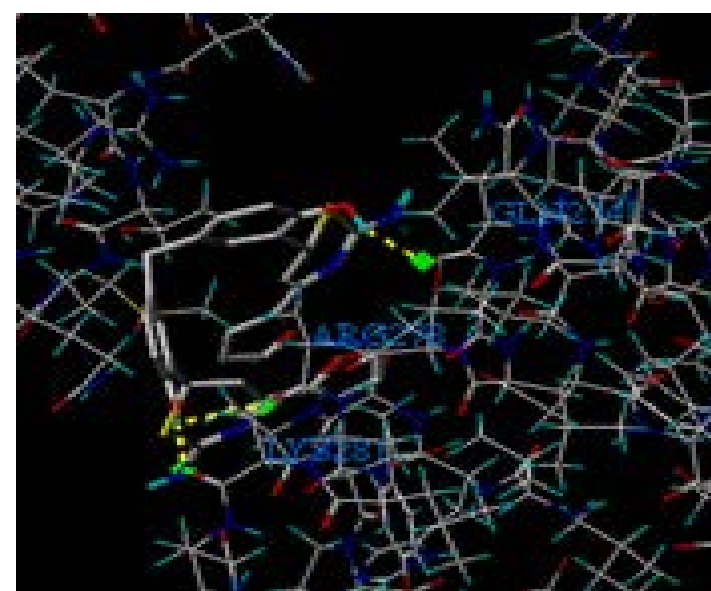

(B)

Figure 2. A. Superimposed binding orientation of docked compound (6b) forming three hydrogen bonds with ARG 278, LYS281, GLN274 shown by yellow colored lines. B. Superimposed binding orientation of docked compound (5b) forming three hydrogen bonds with ARG 278, LYS281, GLN274 shown by yellow colored lines.

\section{$7 \quad$ Discussion}

Ten compounds containing furan and imidazole and thiazine nucleus along with other structural features 
were designed and synthesized using known procedures depicted in Scheme 1 and 2. Scheme 1 involved condensation reaction between substituted ketones and salicyldehide and resulted in the formation of E)-3-(2-hydroxyphenyl)-1-(1H-imidazol-1-yl)prop-2-en-1-one (1a) and E)-1-(furan-2-yl)-3-(2hydroxyphenyl)prop-2-en-1-one 1(b). Compound $1 \mathrm{a}$ and $1 \mathrm{~b}$ were further allowed to react by two ways, one was with thiourea in presence of $\mathrm{KOH}$ and methanol, which resulted in the formation of 2-(2-amino4-(1H-imidazol-1-yl)-6H-1,3-thiazin-6-yl)phenol 2(a) and 2-(2-amino-4-(furan-2-yl)-6H-1,3-thiazin-6yl)phenol 2(b), and the other was with guanidine hydrochloride under basic conditions, which resulted in $3 \mathrm{a}$ and $3 \mathrm{~b}$. Scheme 2 is characterized by reaction of salicyldihyde with trioxane under acidic environment to yield compound 4 . Compound 4 further reacted with substituted aromatic ketones and resulted in condensation products $5 \mathrm{a}$ and $5 \mathrm{~b}$. These compounds were further condensed with urea to form compound $6 \mathrm{a}$ and $6 \mathrm{~b}$.

All synthesized compounds were primarily characterized by Rf values, IR, NMR, Mass study and elemental analysis. The Infrared spectra (IR) of each of the synthesized compounds showed absorption bands which are characteristic of the anticipated structure of the synthesized compounds. Infrared measurements showed the presence of $\mathrm{NH}$ stretching $\left(3303-3666 \mathrm{~cm}^{-1}\right)$ in compounds $2 \mathrm{a}, 2 \mathrm{~b}, 3 \mathrm{a}, 3 \mathrm{~b}, 6 \mathrm{a}$ and 6b. All compounds have exhibited O-H stretching $\left(3210-3350 \mathrm{~cm}^{-1}\right), \mathrm{C}=\mathrm{N}$ stretching $\left(1191-1363 \mathrm{~cm}^{-}\right.$ $\left.{ }^{1}\right)$, C-N stretching (1221-1234 $\left.\mathrm{cm}^{-1}\right)$, C-O stretching (1020-1094 cm $\left.\mathrm{cm}^{-1}\right), \mathrm{C}=\mathrm{C}$ stretching $\left(1448-1610 \mathrm{~cm}^{-1}\right)$. Compound $1 \mathrm{a}, 1 \mathrm{~b}, 5 \mathrm{a}$ and $5 \mathrm{~b}$ have shown $\mathrm{C}=\mathrm{O}$ stretching at $1679-1711 \mathrm{~cm}^{-1}$. All $\mathrm{OH}$ protons were appeared as singlet in ${ }^{1} \mathrm{H}$ NMR at $\delta 5.0-3.2 \mathrm{ppm}$. Peaks at $\delta$ 6.4-7.9 in all the compounds accounted for presence of aromatic groups through ${ }^{1} \mathrm{H}$ NMR. The ${ }^{1} \mathrm{H}$ NMR spectrum corroborated the proton and IR data, clearly displaying the expected signals $\left(\mathrm{C}=\mathrm{C}, \mathrm{C}=\mathrm{O}, \mathrm{C}-\mathrm{O}, \mathrm{C}=\mathrm{N}, \mathrm{C}-\mathrm{N}, \mathrm{C}-\mathrm{S}, \mathrm{CH}, \mathrm{NH}\right.$ and $\left.\mathrm{CH}_{2}\right)$. Mass spectra of compounds (1-10) exhibited molecular ion peak at their expected $\mathrm{m} / \mathrm{z}$ values.

All synthesized compounds were evaluated for antifungal and antibacterial activity using macrotube dilution method. Fluconazole were used as positive control for various fungal strains and ciprofloxacin for bacterial strains for their MIC determination. Preliminary assay was performed for a total of five fungal strains and five bacterial strains (including both gram positive and gram negative strains). The included fungal isolates were Candida albicans (2 strains: ATCC 24433, ATCC 10231), Candida tropicalis ATCC 13803, Aspergillus niger ATCC 9029 and Penicillium chrysogenum ATCC 10002. The included bacterial isolates were Pseudomonas aeruginosa ATCC 9027, Staphylococcus aureus ATCC 6538P, Staphylococcus aureus ATCC 25923, Serratia marcescens ATCC 13880, Escherichia coli ATCC 8739. Table 1 exhibited the antifungal activity of synthesized compounds against various fungal strains. Compound $1 \mathrm{~b}, 2 \mathrm{~b}, 3 \mathrm{~b}, 5 \mathrm{~b}$ and $6 \mathrm{~b}$ have shown remarkable activity $(2-8 \mu \mathrm{g} / \mathrm{mL}$ ) against A.niger ATCC 9029. Compound $5 \mathrm{~b}$ and $6 \mathrm{~b}(2 \mathrm{\mu g} / \mathrm{mL})$ have shown maximum activity against $C$. Albicans ATCC 24433, C. Albicans ATCC $10231(2-8 \mu \mathrm{g} / \mathrm{mL})$ and against C. tropicalis ATCC 13803. Only compound 2b have resulted in good activity $(8 \mu \mathrm{g} / \mathrm{mL})$ against $P$. chrysogenum ATCC 10002. Among all derivatives, compound $5 \mathrm{~b}$ and $6 \mathrm{~b}$ have shown interesting activity against almost all the strains and shown to be equipotent $(2 \mu \mathrm{g} / \mathrm{mL})$ to that of standard fluconazole against C. albicans ATCC 10231. All of the synthesized derivatives were also tested against various bacterial strains. The data reported in Table 2 indicated that compound $3 \mathrm{a}$ and $5 \mathrm{~b}$ were found to have moderate activity against S. aureus ATCC 6538P and S. aureus ATCC 25923. All other compounds have shown antibacterial activity less than the reference drug. In general the compounds showed low antibacterial activity as compared to antifungal activity.

Docking sores of all 10 compounds are shown in Table 3. All the ligands showed good binding against NMT target. The docking results obtained showed hydrogen bond interaction of the best compound number $6 \mathrm{~b}$ with total score value of 6.6574 and Cresh score of -1.955 . This candidate showed appreciable interaction as compared to other molecules, and amino acids residues present around it exhibited reasonable interactions. Amino acid residues ARG 278, LYS281 and GLN274 were found to be involved in hydrogen bond interactions of compound $6 \mathrm{~b}$. Compound $5 \mathrm{~b}$ exhibited hydrogen bonding with ARG 278, LYS281 and GLN274 amino acid residues of NMT with good total score and cresh score. The presence of the furan ring and electron-donating hydroxyl group (compounds $5 \mathrm{~b}$ and $6 \mathrm{~b}$ ) seemed to confer higher antifungal potency than that of other substituted groups. Electronegative oxygen atoms facilitate hydrogen bonding and can be identified as another structural feature for antifungal activity through inhibition of NMT. The best poses of the studied compounds within the active sites of target enzymes are displayed in Fig. 2. 


\section{Conclusions}

A series of ten compounds containing imidazole, furan heterocyclic rings were synthesized and screened for their antifungal activities using macro tube dilution method. Compound 5b and 6b with furan ring were found to be most active against most of the fungal strains used in the study. Docking studies further showed that compound $5 \mathrm{~b}$ and $6 \mathrm{~b}$ possessed good binding scores for fungal $N$ myristoyltransferase (NMT). More studies to optimize the structural feature and mechanism of action of this class of derivatives are required which could be helpful in designing more potent antifungal agents for therapeutic use.

Acknowledgments. The authors acknowledge The Head, School of Pharmacy, DAVV, Indore for providing software facilities.

\section{References}

1. Kawasaki, K., Masubuch, M., Morikam, K., Tsujii S. and Ohtsuka T. (2003) Design and synthesis of novel benzofurans as a new class of antifungal agents targeting fungal N-myristoyltransferase. Bioorganic Medicinal Chemistry Letters, 13, 87-91.

2. Sogabe, S., Masubuchi, M., Niizuma, S. and Aoki Y. (2002) Crystal structures of Candida albicans Nmyristoyltransferase with two distinct inhibitors. Chemistry and Biology, 9,1119-1128.

3. Bhatnagar, R.S. and Futterer, K. (1998) Structure of N-myristoyltransferase with bound myristoylCoA and peptide substrate analogs. Nature Structural Biology, 12, 1091-1097.

4. Boutin, J.A. (1997) Myristoylation. Cellular Signalling, 1,15-39.

5. Sogabe, S.M., Sakata, K., Takaai, A., Morikami, K., Shimma, N. and Winkler F. (2002) Crystal structures of Candida albicans N-myristoyltransferase with two distinct inhibitors. Chemical Biology, 9, 1119-1128.

6. Demirayak, S. and Ucucu, U. (2002) Synthesis and antifungal activities of some aryl (benzofuran-2-yl) ketoximes. Il Farmaco, 57, 609-612.

7. Rival, Y., Grassy, G., Taudou, A. and Ecalle, R. (1991) Antifungal activity in vitro of some imidazo [1,2alpyrimidine derivatives. European Journal of Medicinal Chemistry, 26, 13-18.

8. Silverstri, R. and Artico, M. (2004) Fluoxetine, a Novel Class of anti-Candida Agents. Journal of Medicinal Chemistry, 47, 3924-3926.

9. Kawasaki, K., Masubuchi, M. and Ohtsuka T.(2003) Design and synthesis of novel benzofurans as a new class of antifungal agents targeting fungal N-myristoyltransferase. Bioorganic Medicinal Chemistry Letters, 13, 87-91.

10. Masubuchi, M. , Ebike, H., Liu, P. and Morikami, K. (2003)Synthesis and biological activities of benzofuran antifungal agents targeting fungal N-myristoyltransferase. Bioorganic Medicinal Chemistry, 11, 4463-4478.

11. Wahab, K.M., Jahangir, A.M., Rashid, M.A. and Chowdhary, R. (2005) A new structural alternative in benzo[b]furans for antimicrobial activity. Bioorganic Medicinal Chemistry Letters, 13, 4796-4805.

12. Karaburn, N.G. and Benkil, K.(2006) Synthesis and activities of some aryl [3-(imidazol-1-yl/triazol-1-yl methyle) benzofuran-2-yl]ketoximes. European Journal of Medicinal Chemistry, 41, 651-656.

13. ZHU Jie, SHENG Chun-Quan, ZHANG Min, SONG Yun-Long, CHEN Jun, YU Jian-Xin, YAO Jian-Zhong, MIAO Zhen-Yuan and ZHANG Wan-Nian. (2006) 3D-QSAR Study of a Series of Novel Benzofuran NMT Inhibitors, Chemical Journal of Chinese Universities, 27, 287-29

14. Kirimis, C., Koca, M., Servi, S. and Gur, S. (2009) Synthesis and antimicrobial activity of dinapthol [2,1b]furan-2-yl-methanone and their oxime derivatives. Turkey Journal of Chemistry, 33, 374-380.

15. Reddy, C.S. and Nagaraj, A. J.(2008) Synthesis and biological study of novel bis-chalcones, bis-thiazines and Bis-pyrimidines. Iranian Chemical Society, 5, 262-267.

16. NCCLS, National Committee for Clinical Laboratory Standards. 2002, In Method M27-A2, 2nd ed.: Wayne, Ed.; Vol. 22, pp 1-29. In NCCLS, and method M-38A, 2nd ed.: Wayne Ed.; Vol. 22, pp 1-27. 